Rapid Reviews COVID-19

\title{
Reviews of "Impaired local intrinsic immunity to SARS-CoV-2 infection in severe COVID-19"
}

Alessandro Marcello ${ }^{1}$, Alejandro Berrio²

${ }^{1}$ International Centre for Genetic Engineering and Biotechnology, Molecular Virology, Italy, ${ }^{2}$ Postdoctoral Associate, Duke University, Biology

Published on: Apr 09, 2021

License: Creative Commons Attribution 4.0 International License (CC-BY 4.0). 
To read the original manuscript, click the link above.

Summary of Reviews: This study employs microfluidic devices to test candidate therapeutics blocking SARS-CoV-2 entry and demonstrates amodiaquine efficacy in preclinical models. The claims presented in this work are reliable but could be strengthened through more rigorous model characterization.

\section{Reviewer 1 (Alessandro Marcello) |}

\section{Reviewer 2 (Alejandro Berrio) |}

$$
\begin{aligned}
& \text { RR:C19 Strength of Evidence Scale Key } \\
& \text { प्रमप = Misleading } \\
& \text { प्र००० = Not Informative } \\
& \text { प्रा पि = Potentially Informative }
\end{aligned}
$$

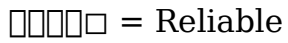

$$
\begin{aligned}
& \text { प्राप्र = Strong }
\end{aligned}
$$

To read the reviews, click the links below. 